\title{
DESEMPENHO DE SUÍNOS DE DOIS CRUZAMENTOS DE LINHAGENS COMERCIAIS CRIADOS EM CAMA SOBREPOSTA
}

\author{
PERFORMANCE TRAITS OF TWO CROSS-BREEDING OF SWINE STRAINS \\ IN DEEP BEDDING
}

\author{
Guimarães, G.G. ${ }^{*}$, Murata, L.S. ${ }^{1 A}$, Mcmanus, C. ${ }^{1}$, Santana, A.P. ${ }^{1}$, Reckziegel, G.C. ${ }^{1 \mathrm{~B}}$, \\ Amâncio, A.S. ${ }^{1}$, Filho, R.M.J. ${ }^{1}$ e Sobrinho, A.J.F. ${ }^{2}$ \\ 'Universidad de Brasilia. Campus Universitário Darcy Ribeiro. CEP 70910-900. Brasília, DF. Brasil. \\ *gisellegoncalvesg@hotmail.com; Amluci@unb.br; Bguilherme@yahoo.com.br \\ ${ }^{2}$ Asa Alimentos. Setor de suínos. CEP 71200-030. Brasília, DF. Brasil. antoniofaria@asaalimento.br
}

\section{PaLAVRAS ChAVE ADICIONAIS}

Conversão alimentar. Espessura de toucinho. Ganho de peso.

\section{RESUMO}

Este experimento foi conduzido para avaliar o desempenho de suínos criados em cama sobreposta, foram utilizados 480 animais, distribuídos em delineamento de blocos ao acaso, num arranjo fatorial $2 \times 2$ (cruzamentos $x$ sexos), com três repetições de quarenta animais por unidade experimental. Foi avaliada a espessura de toucinho (ET) entre a $10^{\mathrm{a}}$ e $11^{\mathrm{a}}$ costela e na altura $\mathrm{P}_{2}$ e área de olho de lombo ( $\mathrm{AOL}$ ) utilizandose ultra-som em tempo real e as características de desempenho. Verificou-se que houve efeito do sexo, onde machos apresentaram resultados superiores para consumo semanal (CS) e diário (CD) de ração, entretanto, a conversão (CA) e eficiência alimentar (EA) apresentaram resultados inferiores quando comparados às fêmeas. Não se observou efeito no ganho de peso diário (GPD) e peso final (PF), entre macho e fêmea. Suínos provenientes de ambos os cruzamentos e sexos apresentaram resultados satisfatórios e podem ser produzidos no sistema de cama sobreposta, entretanto, as fêmeas suínas apresentaram melhor desempenho zootécnico.

\section{SUMMARY}

This experiment was conducted to evaluate the swine performance in deep bedding breeding. Were used 480 pigs in an experimental design of

Recibido: 14-3-07. Aceptado: 2-4-09.

\section{Additional KeYWoRDS}

Backfat thickness. Feed: gain ratio. Weight gain.

randomized blocks, and fatorial arrangement $2 \mathrm{x}$ 2 (crossbreeding $x$ sex), with three replications and forty animals per experimental unit. Were evaluated the pigs performance traits, backfat thickness $(E T)$ between $10^{\text {th }}$ and $11^{\text {th }}$ rib and in the $\mathrm{P}_{2}$ height and loin eye area $(\mathrm{AOL})$ using real-time ultrasond during the experimental period. Sex effect was verified: male presented results better than female for weekly intake (CS) and daily feed intake (CD); however, feed: gain ratio (CA) and feed efficiency (EA) for male were worse than females. There were not differences in average daily gain (GPD), between males and females. Animals from both crossbreeding and sexes showed satisfactory results, perhaps, swine females showed better performance than male and can be used in deep bedding breeding.

\section{INTRODUÇÃO}

O sistema de produção de suínos mais utilizado no Brasil tem sido o intensivo confinado por proporcionar aumento na produção do setor, gerando crescimento da atividade no Brasil. A criação de suínos em cama sobreposta proporciona aos animais desempenho satisfatório, garantindo que os mesmos alcancem o peso de abate 
rapidamente, como no sistema confinado convencional. De acordo com Oliveira (2004) este sistema se distingue dos demais por alojar suínos em baias com dimensões maiores do que no sistema confinado industrial, onde os animais permanecem sobre um leito composto por substrato.

Sabe-se que as respostas para desempenho de suínos apresentam diferenças entre machos castrados e fêmeas, em função das variações nutricionais que são exigidos entre si. Assim, a criação de suínos com separação de sexos deve ser vista como estratégia que proporcione melhor desempenho aos animais, levando-se em consideração as exigências nutricionais a que lhes são atribuídas.

Segundo Sobestiansky et al. (1998) os machos castrados consomem mais alimento e podem apresentar ganho de peso superior quando comparados com as fêmeas. Entretanto, as fêmeas apesar de consumirem menos alimento têm sido mais eficientes na deposição de carne na carcaça quando comparados com os machos castrados.

Para obtenção de suínos que proporcionem bom desempenho tem sido importante observar as diferentes linhagens comerciais disponíveis no mercado. Sendo necessário a obtenção de animais que apresentem um crescimento rápido, pois esses são os mais econômicos, não só porque consomem menos ração em função do tempo, como também em função de sua capacidade de transformar alimentos em carne (Bertol et al., 2001).

O objetivo do trabalho foi estudar o desempenho de suínos de dois cruzamentos de linhagens comerciais com sexos separados na fase de crescimento e terminação criados em cama sobreposta no Distrito Federal.

\section{MATERIALE MÉTODOS}

O experimento foi realizado em granja comercial de produção de suínos em camasobreposta na região Centro-Oeste do Bra- sil. Durante a fase experimental a região apresentou clima com estação definida, quente e úmida. Segundo a classificação climatológica de Köppen, o clima foi Aw (tropical de savana).

Foram utilizados 480 suínos na fase de crescimento-terminação, apresentaram peso médio inicial de $20,95 \mathrm{~kg}$ e idade média de 60 dias e peso médio final de $110 \mathrm{~kg}$ e idade média de 180 dias. O período experimental foi de 120 dias. A fase de crescimento e terminação compreendeu o período de 60 a 120 dias e de 120 a 180 dias de vida, respectivamente.

Os animais experimentais foram obtidos a partir de dois cruzamentos de linhagens comerciais. O cruzamento A foi composto pela reprodução de fêmea da linhagem Dalland e macho da linhagem Agroceres e o cruzamento B foi composto pela reprodução da fêmea da linhagem DanBred e macho da linhagem Agroceres.

$\mathrm{O}$ delineamento experimental foi em blocos casualizados, distribuídos em esquema fatorial $2 \times 2$, composto por dois cruzamentos de linhagens e dois sexos. Foi considerado como bloco a seqüência de alojamentos, com 3 repetições de 40 animais por unidade experimental.

Durante o experimento foram utilizados três galpões comerciais de $100 \mathrm{~m}$ cada, que possuíam características construtivas similares, com pilares e treliças em aço galvanizado, cobertura em duas águas com telhas de amianto, lanternim no sentido longitudinal da cumeeira, projeções de beiras em $1,5 \mathrm{~m}$ e pé-direito de $3,0 \mathrm{~m}$. As edificações eram dispostas em linha, sob a mesma orientação leste-oeste e eqüidistante em 10 $\mathrm{m}$ entre cada prédio. $\mathrm{O}$ substrato utilizado como cama foi a casca de arroz nova com profundidade de $30 \mathrm{~cm}$.

Foram distribuídos dentro do barracão equidistantemente 4 baias, onde cada baia comportou 40 animais, totalizando 160 animais utilizados por período. As unidades experimentais foram separadas do restante do barracão utilizando-se telas metá- 


\section{DESEMPENHO DE SUÍNOS CRIADOS EM CAMA SOBREPOSTA}

licas gradeadas móveis com altura de $60 \mathrm{~cm}$.

Os animais permaneceram na mesma cama por todo período experimental, não houve revolvimento de cama ao longo do experimento, periodicamente foi acrescentando cama nova nas regiões com maior umidade.

No centro de cada baia, fixo a uma plataforma de concreto havia um comedouro automático com capacidade para $100 \mathrm{~kg}$ de ração em fluxo contínuo com acesso por ambos os lados, em cada extremidade havia dois bebedouros tipo chupeta acoplados ao comedouro, possibilitando o consumo de ração na forma úmida ou seca.

Os galpões foram equipados com ventiladores e nebulizadores automáticos, sendo que os primeiros foram acionados quando a temperatura apresentava-se acima de $23,5^{\circ} \mathrm{C}$, e o segundo foi acionado, quando a temperatura estava acima de $25,5^{\circ} \mathrm{C}$.

Durante o período experimental foram anotadas diariamente às 16:00 a temperatura e umidade relativa do ar máxima e mínima do ambiente com o uso de um termohigrômetro de termômetros de máxima e mínima (in) instalados a uma altura correspondente á dos animais e de máxima e mínima (out) instalados no meio do galpão.

As dietas fornecidas aos animais foram formuladas de acordo com as exigências em nutrientes para a fase de crescimento, terminação e abate de acordo com a determinação da empresa, como pode ser observado na tabela I. Os suínos receberam ração de crescimento dos 20 aos $70 \mathrm{~kg}$, de terminação dos 70 aos $100 \mathrm{~kg}$ e de abate dos 100 aos $110 \mathrm{~kg}$ de peso. A ração e a água foram fornecidos à vontade durante o período experimental.

No início e ao fim do experimento os suínos foram pesados individualmente na granja em balança eletrônica. Semanalmente foi realizada a pesagem em grupos dos animais por sexo por cruzamento até a última semana do experimento, obtendo-se o peso inicial (PI), peso final (PF), respectivos consumos de ração computado, para deter- minação do consumo diário (CD), consumo semanal (CS), conversão alimentar (CA) $(\mathrm{CA}=\mathrm{CD} / \mathrm{GPD})$ e eficiência (EA) $(\mathrm{EA}=\mathrm{GPD} /$ $\mathrm{CD})$.

Dez suínos de cada baia foram selecionados aleatoriamente e identificados com brincos para avaliação quanto a ET e AOL, totalizando 40 animais. Para a realização das medidas ultra-sônicas de ET e AOL com animal in vivo, utilizou-se um conjunto de equipamentos constituído de uma ecocâmera ALOKA SSD 500 um transdutor linear de $3 \mathrm{MHz}$. A mensuração da ET foi realizada uma vez por mês durante o experimento na granja, e uma avaliação no foi realizada no frigorífico durante o período de descanso, permitindo cinco avaliações nos 40 animais. Enquanto que, a avaliação da AOL foi realizada somente no frigorífico no mesmo momento da avaliação da ET.

Para as avaliações de ET e AOL, o animal

Tabela I. Composição calculada das rações experimentais. (Calculated composition of the experimental diets).

\begin{tabular}{lrcc}
\hline & \multicolumn{3}{c}{ Dieta experimental } \\
& C & T & A \\
\hline Proteína bruta $^{1}$ & 19,0 & 16,8 & 14,7 \\
Energia metabolizável $^{2}$ & 3301 & 3301 & 3202 \\
Extrato etéreo $^{1}$ & 4,2 & 4,0 & 3,8 \\
Fibra bruta $^{1}$ & 3,2 & 3,0 & 2,5 \\
Cálcio $^{1}$ & 0,78 & 0,70 & 0,75 \\
Fósforo total $^{1}$ & 0,53 & 0,45 & 0,50 \\
Fósforo disponível $^{1}$ & 0,43 & 0,32 & 0,35 \\
Lisina total $^{1}$ & 1,05 & 0,90 & 0,80 \\
Metionina total $^{1}$ & 0,32 & 0,27 & 0,24 \\
Cistina total $^{1}$ & 0,30 & 0,28 & 0,25 \\
Aminoácidos sulfurados $^{1}$ totais $^{1}$ & 0,63 & 0,55 & 0,49 \\
Treonina total $^{1}$ & 0,70 & 0,62 & 0,55 \\
Triptofano total $^{1}$ & 0,22 & 0,19 & 0,15 \\
Leucina total $^{1}$ & 1,67 & 1,53 & 1,50 \\
Isoleucina total $^{1}$ & 0,77 & 0,68 & 0,50 \\
Arginina total $^{1}$ & 1,24 & 1,07 & 0,85 \\
Colina total $^{3}$ & 1182 & 1070 & 837 \\
\hline & & &
\end{tabular}

C: Crescimento; T: Terminação; A: Abate.

${ }^{1} \% ;{ }^{2} \mathrm{kcal} / \mathrm{kg} ;{ }^{3} \mathrm{mg} / \mathrm{kg}$. 
foi contido em pé sobre uma superfície plana, onde procedeu-se a limpeza e em seguida a tricotomia no local correspondente as mensurações, que foram entre a última vértebra torácica e primeira vértebra lombar $\left(10^{\mathrm{a}}\right.$ e $11^{\mathrm{a}}$ costela) e entre a última vértebra lombar $\left(\mathrm{P}_{2}\right)$ a $5 \mathrm{~cm}$ da linha dorsal. Em seguida colocou-se gel no local que permitiu perfeito ajustamento do transdutor ao corpo do animal.

Os suínos foram submetidos a um jejum alimentar pré-abate de 16 horas com fornecimento de água a vontade. O carregamento e transporte dos animais para o frigorífico foram realizados no início da manhã, e percorreram uma distância de $80 \mathrm{~km}$ entre a granja e o frigorífico.

Ao chegarem ao frigorífico os suínos foram alojados em baias onde foram pesados individualmente em balança eletrônica digital e submetidos à identificação por tatuagem, em seguida obedeceram ao período de descanso estabelecido pela indústria.

Durante este período no frigorífico os animais foram submetidos às análises de ET e AOL, onde foram realizadas limpeza e tricotomia no animal no local correspondente a mensuração, como foi relatado anteriormente, utilizando o ultra-som ALOKA SSD 500, uma probe de 7,5 cm e 3,5 $\mathrm{MHz}$ para as medidas longitudinais de ET e uma probe de $14 \mathrm{~cm} \mathrm{e} \mathrm{3,5} \mathrm{MHz,} \mathrm{uma} \mathrm{guia}$ acústica de polivinil ou standoff para medidas transversais de AOL de cada animal.

Os valores dos dados obtidos foram analisados pelo software Statistical Analysis System, SAS (1999) pela aplicação dos procedimentos GLM (análise de variância), CORR (correlação), testes de médias (Tukey $5 \%$ ). As variáveis estudadas foram analisadas utilizando o seguinte modelo estatístico:

$$
Y_{i j k l}=\mu+G_{i}+P_{j}+T_{k}+(G P)_{i j}+E_{i j k l},
$$

sendo:

$Y_{i j k 1}=$ Conjunto de variável dependente; $\mu=$ Média observada em $Y_{i j \mathrm{kl} i}$
$G_{i}=$ Efeito do cruzamento $\left(i_{1}=\right.$ cruzamento $A ; i_{2}=$ cruzamento B);

$P_{j}=$ Efeito do sexo $\left(j_{1}=\right.$ macho; $j_{2}=$ fêmea $)$;

$\mathrm{T}_{\mathrm{k}}=$ Efeito do bloco $\left(\mathrm{k}_{1}=\right.$ repetição $1 ; \mathrm{k}_{2}=$ repetição $2 ; k_{3}=$ repetição 3 );

$(G P)_{i j}=$ Efeito da interação entre cruzamento e sexo;

$E_{i j k l}=$ Erro experimental associada à $Y_{i j k l}$

\section{RESULTADOSEDISCUSSÃO}

$\mathrm{Na}$ tabela II estão apresentadas às análises de variância para as características de desempenho entre dois cruzamentos de linhagens comerciais que foram estudadas, observou-se que o GPS e GPD não apresentaram diferença $(p>0,05)$ entre machos e fêmeas, entretanto as características de CS $(p<0,001), C D(p<0,001), C A(p<0,05)$ e EA $(\mathrm{p}<0,05)$ apresentaram diferença, resultados que concordam a proposta Torres Filho et al. (2005) onde machos castrados e as fêmeas apresentam consumo de ração e CA diferenciados, sendo que os primeiros apresentaram resultados superiores.

Observou-se que não houve diferença $(p>0,05)$ entre os cruzamentos estudados quanto ao desempenho dos animais sugerindo que ambos os cruzamentos são adequados para a criação em cama sobreposta.

Verificou-se que não houve efeito significativo $(p>0,05)$ para as interações entre sexo*idade; cruzamento*idade e sexo*cruzamento*idade sobre as características estudadas durante o período experimental (tabela II).

Na tabela III pode-se observar os resultados de desempenho, ET e a AOL dos suínos criados em cama sobreposta durante $o$ período experimental. Os machos apresentaram ganho de peso superior em 1,3\% quando comparados com as fêmeas, os valores não diferiram estatisticamente $(p>0,05)$ para esta característica, constatando-se que ambos obtiveram GPD e ganho de peso total (GPT) semelhantes durante o período experimental.

Durante a fase de crescimento e terminação a temperatura média observada foi de

Archivos de zootecnia vol. 60, núm. 229, p. 14. 


\section{DESEMPENHO DE SUÍNOS CRIADOS EM CAMA SOBREPOSTA}

Tabela II. Análise de variância das características de desempenho de suínos criados em cama sobreposta. (Analysis of variance of the characteristics of swine performance breeding in deep bedding).

\begin{tabular}{lcccccc}
\hline Parâmetros & GPS & GPD & CS & CD & CA & EF \\
\hline Sexo & NS & NS & $* * *$ & $* * *$ & $*$ & $*$ \\
Cruzamentos & NS & NS & NS & NS & NS & NS \\
Sexo*Idade & NS & NS & NS & NS & NS & NS \\
Cruzamentos*Idade & NS & NS & NS & NS & NS & NS \\
Sexo*Cruzamentos*Idade & NS & NS & NS & NS & NS & NS \\
$R^{2}$ & 0,41 & 0,41 & 0,73 & 0,79 & 0,67 & 0,7 \\
CV & 19,91 & 19,90 & 15,23 & 12.48 & 20,00 & 20,20 \\
Média & 5,36 & 0,77 & 14,79 & 2,16 & 2,92 & 0,37 \\
\hline
\end{tabular}

${ }^{*} p<0,05 ;{ }^{* *} p<0,01 ;{ }^{* * *} p<0,001$.

GPS: Ganho de peso Semanal; GPD: Ganho de peso diário; CS: Consumo semanal; CD: Consumo diário; CA: Conversão alimentar; EF: eficiência; $R^{2}$ : Coeficiente de determinação; CV: Coeficiente de variação.

$24,5^{\circ} \mathrm{C}$, apresentando-se $7^{\circ} \mathrm{C}$ acima da temperatura ideal recomendada por Whittemore (1980) e MAPA (2000) para suínos nesta fase da criação. Segundo Laganá et al.(1988) e Hannas (1999) a temperatura e a umidade tornam-se fatores limitantes na obtenção da produtividade, situação que se agrava nas fases de crescimento e terminação, pois ocorre aumento da sensibilidade ao calor pelo animal.

Tabela III. Médias de desempenho de suínos criados em cama sobreposta. (Averages of swine performance breeding in deep bedding).

\begin{tabular}{|c|c|c|c|c|c|}
\hline \multirow[b]{2}{*}{ Parâmetros } & \multicolumn{2}{|c|}{ Sexo } & \multirow{2}{*}{$\begin{array}{l}\text { Valor } \\
\text { de P }\end{array}$} & \multirow{2}{*}{$\begin{array}{l}\text { CV } \\
(\%)\end{array}$} & \multirow[t]{2}{*}{$\mathrm{R}^{2}$} \\
\hline & macho & fêmea & & & \\
\hline Peso final $(\mathrm{kg})$ & 114,03 & 111,88 & NS & 3,88 & 0,44 \\
\hline Ganho de peso total $(\mathrm{kg})$ & 91,34 & 90,39 & NS & 4,86 & 0,31 \\
\hline Ganho de peso diário $(\mathrm{g})$ & 0,770 & 0,760 & NS & 4,86 & 0,31 \\
\hline Consumo total $(\mathrm{kg})$ & 264,90 & 241,30 & 0,001 & 3,49 & 0,77 \\
\hline Consumo diário (kg) & 2,24 & 2,05 & 0,001 & 3,42 & 0,78 \\
\hline Conversão alimentar & 2,88 & 2,66 & 0,05 & 3,44 & 0,77 \\
\hline Eficiência alimentar & 0,360 & 0,380 & 0,05 & 3,23 & 0,78 \\
\hline ET entre $10^{\mathrm{a}}$ e $11^{\mathrm{a}}$ costela, in vivo $(\mathrm{mm})$ & 6,23 & 6,01 & NS & 30,0 & 0,02 \\
\hline ET na $\mathrm{P}_{2}$, in vivo $(\mathrm{mm})$ & 16,23 & 13,42 & NS & 30,190 & 0,07 \\
\hline AOL $10^{2}$ e $11^{a}$ costela, in vivo $\left(\mathrm{cm}^{2}\right)$ & 46,64 & 47,86 & NS & 14,480 & 0,23 \\
\hline $\mathrm{AOL}$ na $\mathrm{P}_{2}$, in vivo $\left(\mathrm{cm}^{2}\right)$ & 41,98 & 43,26 & NS & 15,86 & 0,08 \\
\hline
\end{tabular}

ET $10^{\mathrm{a}}$ e $11^{\mathrm{a}}$ costela: médias de espessura de toucinho entre a $10^{\mathrm{a}}$ e $11^{\mathrm{a}}$ costela (última vértebra torácica e primeira vértebra lombar) de suínos vivos realizadas no frigorífico; ET na $P_{2}$ : médias de espessura de toucinho na altura $P_{2}$ (entre a décima e a última vértebra lombar) em suínos vivos realizadas no frigorífico; $\mathrm{AOL} 10^{\mathrm{a}}$ e $11^{\mathrm{a}}$ costela: médias de área de olho de lombo entre a $10^{\mathrm{a}}$ e $11^{\mathrm{a}}$ costela de suínos vivos realizadas no frigorífico; $A O L$ na $P_{2}$ : médias de área de olho de lombo na altura $P_{2}$ realizadas no frigorífico; $\mathrm{CV}$ : Coeficiente de variação; $\mathrm{R}^{2}$ : Coeficiente de determinação. 
A URA mínima e máxima na fase de crescimento variou entre $50 \pm 5$ e $80 \pm 3 \%$, respectivamente, e para a fase de terminação variou entre $57 \pm 8$ e $83 \pm 4 \%$, respectivamente. Esta variação em conjunto com a variação térmica pode causar redução na porcentagem de perda de calor, segundo Nääs e Rodrigues (1999) a elevação da URA de 45 para $90 \%$, a uma temperatura ambiental de $20^{\circ} \mathrm{C}$, pode reduzir em $8 \%$ as perdas de calor de suínos.

Segundo Silva (1999) quando a URA apresenta valores elevados, este torna-se fator limitante para os animais homeotermos adultos, principalmente quando a temperatura se aproxima dos $30^{\circ} \mathrm{C}$. Segundo o autor, para suínos na fase de crescimento com aproximadamente $30 \mathrm{~kg}$ em conforto térmico $\left(14\right.$ a $\left.24^{\circ} \mathrm{C}\right)$, a umidade ótima fica entre $50 \mathrm{e}$ $70 \%$.

Segundo O'Grady et al. (1985), Muller (1989), Fialho (1994), Nienaber et al. (1996), Silva (1999), Orlando et al. (2001) e Kerr et al. (2003) grande parte dos suínos submetidos ao estresse por calor não apresentam redução no consumo de ração, mas a intensidade do estresse térmico ocasiona desvios nutricionais para a manutenção da homeotermia prejudicando o ganho de peso, sendo que parte da energia consumida é redirecionada para os processos de termorregulação. Considerando-se o consumo total (CT) e CD do período experimental, observou-se que houve diferença $(p<0,05)$ entre machos e fêmeas, onde machos ao longo do experimento consumiram mais ração, entretanto estes apresentaram uma CA e EA piores em relação às fêmeas. Sugere-se que com o aumento da temperatura ambiente dos machos da presente pesquisa tenderam a utilizar a energia consumida para manter a homeotermia, prejudicando o ganho de peso.

Diferenças no desempenho entre machos e fêmeas são observados na fase de crescimento e terminação, pois, de acordo com Fuller (1980) estas diferenças resultam de mudanças que acompanham o desen-
Tabela IV. Correlação de dois cruzamentos de suínos criados em cama sobreposta. (Correlation of two swine crossings created breeding in deep bedding).

\begin{tabular}{lcccccc}
\hline & GPS & GPD & CS & CD & CA & EA \\
\hline GPD & 0,99 & & & & & \\
CS & 0,14 & 0,14 & & & & \\
CD & 0,12 & 0,12 & 0,84 & & & \\
CA & $-0,61$ & $-0,61$ & 0,53 & 0,66 & & \\
EA & 0,60 & 0,60 & $-0,56$ & $-0,69$ & $-0,95$ & \\
PF & $-0,09$ & $-0,09$ & 0,57 & 0,76 & 0,66 & $-0,68$ \\
\hline
\end{tabular}

GPS: Ganho de peso semanal; CS: Consumo semanal; CD: Consumo diário; CA: Conversão alimentar; EA: Eficiência alimentar e PF: Peso final.

volvimento sexual do animal, o que não pode ser constatado na fase inicial do seu desenvolvimento.

Xue et al.(1997), no entanto, citaram que hormônios andrógenos e estrógenos exercem seus efeitos anabólicos por diferentes mecanismos no organismo dos suínos, e a ausência destes hormônios sexuais em machos castrados, proporcionam aumento do consumo de alimento e redução da capacidade de deposição de proteína aos tecidos musculares, quando comparados com fêmeas, o que pode ter sido a causa do maior consumo alimentar nos machos.

$\mathrm{Na}$ tabela III pode-se verificar que os machos apresentaram valores de ET superiores em 3,5 e $20 \%$ entre a $10^{\mathrm{a}}$ e $11^{\mathrm{a}}$ costela e na altura $\mathrm{P}_{2}$, quando comparados às fêmeas. Estes valores não apresentaram diferença estatística, entretanto pode ter sido o suficiente para provocar mudança no ganho de peso dos machos, o que os tornou menos eficientes em dissipar o calor. Assim, machos castrados apresentam maior deposição de gordura subcutânea e menor área de contato com o ambiente, aumentando o isolamento térmico, o que dificulta a dissipação de calor por condução e convecção, tornando-os menos eficientes para dissipar calor do que as fêmeas (Muller, 1989). 


\section{DESEMPENHO DE SUÍNOS CRIADOS EM CAMA SOBREPOSTA}

Na tabela IV estão apresentadas às correlações entre desempenho dos suínos criados em cama sobreposta. Observou-se que GPD apresentou correlação positiva elevada com o GPS. O CS e CD apresentaram correlação positiva baixa com o GPS e GPD, mostrando que, apesar do consumo ter sido elevado este não provocou aumento do ganho de peso dos mesmos. Por outro lado, quando o CD mostrou-se elevado, conseqüentemente aumentou-se o CS.

A CA demonstrou correlação negativa com o GPS e GPD, o que está de acordo com Ludwig et al. (1978) onde os animais com melhor ganho de peso demonstraram naturalmente melhora na CA. Entretanto a CA apresentou correlação positiva para CS e CD, demonstrando que a CA piorou quando houve aumento no consumo alimentar dos suínos.

Para a EA verificou-se correlação positiva em relação ao GPS e GPD, indicando que a EA apresentou-se eficiente quando houve

\section{BIBLIOGRAFIA}

Bertol, T.M., Ludke, J.V. e Bellaver, C. 2001. Efeito do peso do suíno em terminação ao início da restrição alimentar sobre o desempenho e a qualidade da carcaça. Rev. Bras. Zootecn., 30: 1-10.

Fialho, E.T. 1994. Influência da temperatura ambiental sobre a utilização da proteína e energia em suínos em crescimento e terminação. Em: Simpósio Latino-Americano de Nutrição de Suínos. CBNA. São Paulo. pp. 63-83.

Fuller, M.F. 1980. Recent advances in animal nutrition. Butterworths. London. pp. 157-159.

Hannas, M.I. 1999. Aspecto fisiológico e a produção de suínos em clima quente. Fundação de Estudos Agrários. Piracicaba. pp. 1-33.

Kerr, B.J., Yen, J.T. and Nienaber, J.A. 2003. Influences of dietary protein level, amino acid supplementation and environment temperature on performance, body composition, organ weights and total heat production of growing pigs. J. Anim. Sci., 81: 1998-2007.

Laganá,C., Nããs, I.A. e Tolon, Y.B. 1998. Lámina de água em corrales de gestación para suínos. Agrociência, 14: 79-83. elevação do ganho de peso, no entanto houve correlação negativa com CS e CD, onde a EA foi menor quando o consumo de ração foi elevada. Para a CA, a EA apresentou correlação alta negativa.

Em relação ao PF verificou-se correlação negativa com o GPS, GPD e EA, quando os suínos alcançaram a fase de terminação o PF piorou o GPD, GPS, EA e CA nos animais. O aumento no consumo alimentar não resultou em melhor PF.

\section{CONCLUSÃO}

Recomenda-se criação de suínos em cama sobreposta com sexos separados com dietas específicas para cada sexo. O desempenho de ambos os cruzamentos foi similar, podendo ser utilizados para a criação em cama sobreposta. As fêmeas suínas apresentaram melhor desempenho zootécnico em cama sobreposta.

Ludwig, A., Irgang, R. e Saralegui, W. 1978. Índice de seleção para suínos Landrace testados nas estações de avaliação. Empresa Brasileira de Pesquisa Agropecuária. Centro nacional de Pesquisa de Suínos. CNPSA. Concórdia. pp. 1-5. MAPA. 2000. Normas e padrões de nutrição e alimentação animal. Ministério da Agricultura e do Abastecimento. Brasília, DF. Brasil. pp. 125130.

Müller, P.B. 1989. Bioclimatologia aplicada aos animais domesticados. $3^{a}$ edição. Ed. Sulina.Porto Alegre. pp. 67-89.

Nääs, I. e Rodrigus, E.H.V. 1999. Qualidade do ambiente para a produção de suínos na gestação e maternidade. Em: I.J.O. Silva (Ed.) Ambiência e qualidade na produção industrial de suínos. Fundação de Estudos Agrários "Luiz de Queiroz". Piracicaba. pp. 112-130.

Nienaber, J.A., Hahn, G.L., McDonald, T.P. and Korthals, R.L. 1996. Feeding patterns and swine performance in hot environments. Trans. ASAE, 39: 195-202.

O'Grady, J.F., Lynch, P.B. and Kearney, P.A. 1985. Voluntary feed intake by lactating sows. Livest. 


\section{GUIMARÃESETAL.}

Prod. Sci., 12: 355-365.

Oliveira, P.A.V. e Higarashi, M.M. 2004. Produção de suínos em sistema de cama sobreposta. Em: P.A.V. Oliveira (Ed.) Tecnologias para o manejo de resíduos na produção de suínos. Manual de Boas Práticas. Embrapa Suínos e Aves. Concórdia. pp. 57-67.

Orlando, U.A.D., Oliveira, R.F.M., Donzele, J.L., Ferreira, A.S., Resende, W.O. e Freitas, L.S. 2001. Níveis de proteína bruta da ração para leitões dos 30 aos $60 \mathrm{~kg}$ mantidas em ambientes de conforto térmico. Rev. Bras. Zootecn., 30: 1760-1766

SAS. 1999. Statistical Analysis Systems. User's guide. SAS Institute Inc. North Caroline.

Silva, I.J.O. 1999. Sistema naturais e artificiais do controle do ambiente. Climatização. Fundação de Estados Agrários. Piracicaba. pp. 81-112. Sobestiansky, J., Wentz, I. e Silveira, P.R.S. 1998. Suinocultura intensiva: Produção, manejo e saúde do rebanho. Embrapa. CNPSA. SPI. Concórdia. pp. 267-301.

Torres Filho, M.A., Moreira, J.A., Berto, D.A., Albuquerque, R. e Schammass, E.A. 2005. Energia metabolizável e lisina digestível para suínos na fase de crescimento, criados em condições de segregação sanitária. Rev. Bras. Zootecn., 34: 1980-1989.

Whittemore, C. 1980. Guia moderno da suinocultura. Editora Presença Ltda. Lisboa. pp. 195-295.

Xue, J.L., Dial, G.D. and Pettigrew, J.E. 1997. Performance, carcass, and meat quality advantages of boars over barrow: A literature review. J. Swine Health Prod., 5: 21-28.

Archivos de zootecnia vol. 60, núm. 229, p. 18. 